\title{
Family carer support in home and hospital: a cross-sectional survey of specialised palliative care
}

\author{
Maarten Vermorgen, ${ }^{\oplus 1}$ Aline De Vleminck, ${ }^{1}$ Kathleen Leemans, ${ }^{1,2}$ \\ Lieve Van den Block, ${ }^{1}$ Chantal Van Audenhove, ${ }^{3}$ Luc Deliens, ${ }^{1,4}$ \\ Joachim Cohen ${ }^{1}$
}

\begin{abstract}
${ }^{1}$ End-of-Life Care Research Group, Vrije Universiteit Brussel \& Ghent University, Brussels, Belgium

${ }^{2}$ Department of Radiotherapy, Brussels University Hospital, Brussels, Belgium ${ }^{3}$ LUCAS Center for Care Research and Consultancy, University of Leuven, Leuven, Belgium ${ }^{4}$ Department of Public Health and Primary Care, Ghent University, Ghent, Belgium
\end{abstract}

\section{Correspondence to} Mr Maarten Vermorgen, End-ofLife Care Research Group, Vrije Universiteit Brussel \& Ghent University, Brussels, Belgium; maarten.vermorgen@vub.be

Received 5 February 2019 Revised 3 April 2019 Accepted 23 April 2019

\section{Check for updates}

(c) Author(s) (or their employer(s)) 2019. No commercial re-use. See rights and permissions. Published by BMJ.

To cite: Vermorgen $\mathrm{M}, \mathrm{De}$ Vleminck A, Leemans $\mathrm{K}$, et al. BMJ Supportive \& Palliative Care Epub ahead of print: [please include Day Month Year]. doi:10.1136/ bmispcare-2019-001795

\section{ABSTRACT}

Objectives To evaluate: (1) to what extent family carers of people supported by specialised palliative care services felt they had been provided with information, support and aftercare and (2) how this varied by type of palliative care service, length of enrolment and characteristics of deceased.

Methods A cross-sectional postal survey was conducted using a structured questionnaire with nine items on information, support and aftercare provided by specialised palliative care services to family carers. Flemish family carers of people who had made use of specialised palliative care services at home or in hospital were contacted.

Results Of all primary family carers (response rate of $53.5 \%$ resulting in $n=1504$ ), $77.7 \%$ indicated they were asked frequently by professionals how they were feeling. Around $75 \%$ indicated they had been informed about specific end-of-life topics and around 90\% felt sufficiently supported before and immediately after the death. Family carers of people who had died in a palliative care unit, compared with other types of specialised palliative care services, indicated having received more information, support and aftercare.

Conclusions Family carers evaluate the professional assistance provided more positively when death occurred in a palliative care unit. Policy changes might be needed to reach the same level of care across all specialised palliative care services.

\section{INTRODUCTION}

Family carers are the primary providers of end-of-life care; ${ }^{1}$ they often provide the person who is dying with emotional support, physical and symptom care, medication management and support with practical affairs such as the (instrumental) activities of daily living and domestic work. ${ }^{2}$ Even though in hindsight providing care for a dying person is often evaluated as a rewarding experience, ${ }^{34}$ evidence shows that this responsibility can have adverse outcomes such as feelings of uncertainty, helplessness, distress or anxiety and depression. ${ }^{56}$

Support from professional healthcare providers may help to prevent or reduce some of the burden and negative consequences of this ${ }^{7-9}$ and may enable those doing this work to gain the knowledge required to get better and more empowered in their caregiving role. ${ }^{10-12}$ While being more prepared for the death before it happens has been linked to lower levels of long-term bereavement distress, ${ }^{13}$ family carers may benefit from bereavement support after the death as well. The UK National Institute for Clinical Excellence has suggested that all family carers should at a minimum have access to information about the process of bereavement and the available options for support. ${ }^{14}$ Where the care situation is more complex, support from specialised palliative care services (SPCSs) may be beneficial. These are services with a holistic approach that also provide palliative care and support to other professional providers and to family carers. ${ }^{15}$ According to the WHO, ${ }^{16}$ such services should at least evaluate the social, emotional and spiritual/existential distress of family members.

Even though palliative care is defined as an approach with a core mission to attend to both the person who is dying and those close to them, ${ }^{17}$ intervention studies addressing end-of-life care needs are still predominantly patient centred. ${ }^{8}$ At the same time, studies show that many family carers who provide informal care to a person dying from cancer experience difficulties in obtaining crucial informa$\operatorname{tion}^{18-21}$ and perceive a lack of tailored 
practical $^{19} 22$ and emotional support. ${ }^{19} 23$ In addition, an extensive survey of European SPCSs has demonstrated that $18 \%$ of them do not provide any form of bereavement care and only one in three have developed formal guidelines on bereavement support. ${ }^{24}$ What has not been studied for a broad range of SPCSs, however, is the extent to which family carers of persons with any serious illness receive professional support prior to bereavement when a SPCS is involved at the end of life.

Therefore, this study addresses the following research questions: (1) to what extent do family carers of people who received specialised palliative care perceive to have been provided with information, support and aftercare; (2) does receiving information, support and aftercare vary by context, for example, the type of SPCS, the length of enrolment and the characteristics of the deceased.

\section{METHODS}

\section{Study design and study population}

This cross-sectional survey of bereaved family carers was conducted as a part of a larger study evaluating SPCSs through a range of quality indicators. ${ }^{25}{ }^{26} \mathrm{~A}$ family carer is defined here as any person who cares for a family member or significant other confronted with difficulties due to serious illness. Data were collected at four specific moments in time (a 'snapshot' approach), between November 2014 and May 2016, as this enabled participating services to contact a large number of family carers with minimal effort. A questionnaire was provided to the bereaved person most closely involved in caring for someone who had died in the previous 4 weeks to 4 months and was at least 18 years old and enrolled in an SPCS at home or in hospital at the time of death. We opted for this time period to give family carers some time to grief, while also minimising the possibility of recall bias.

\section{Setting}

In Belgium, SPCSs include: (1) mobile multidisciplinary palliative home care teams (HCTs), which mainly help professionals (eg, general practitioners and nurses), and sometimes family carers, in providing palliative care in the home environment; (2) palliative care units (PCUs) in or associated with a hospital that provide around-the-clock support for patients and family carers with more complex needs and (3) multidisciplinary mobile hospital-based palliative support teams (PSTs) whose primary aim is to support professional carers in different wards within the hospital, although they occasionally also provide more direct support for the person who is dying and those close to them. ${ }^{15}$ Questionnaires were sent to family carers in the 34 Flemish palliative care services that had volunteered to participate in the evaluation: three HCTs, 17 PCUs and 14 PSTs. No participants were included via palliative day care centres or palliative care providers in nursing homes. In table 1 , an overview of the participating services and the number of bereaved people is presented for each measurement period.

\section{Questionnaire}

The nine items used in the structured questionnaire for family carers to measure the provision of information, support and aftercare were translated and adopted from previously validated items in existing questionnaires and were tested on family carers within nine SPCSs in Flanders. ${ }^{25}$ Eight items were adopted from the Consumer Quality Index Palliative Care (CQ-Index $\mathrm{PC})^{2728}$ : 'did you receive information about your relative's condition?' (modification); 'did you get information about the pros and cons of different treatments?' (modification); 'did you get information about the impending death?'; 'did the professional carers talk to you about what it meant to you to care for your sick relative?'; 'did the professional carers ask how you were feeling?'; 'did you feel supported by the professional carers immediately after the death of your relative?'; 'were the possibilities of aftercare pointed out to you after the death of your relative?'; and 'was there a farewell or staff appraisal interview that looked back on the care and treatment that was provided?'. The item 'did you feel that the professional carers gave you all the help and support you needed to care for your relative?' was adopted from the Views Of Informal Carers - Evaluation of Services (VOICES) questionnaire. ${ }^{29}$ Additionally, sociodemographic data about the person who had died and information about the type of palliative care service they were enrolled in and the length of time they had been enrolled were taken from the person's records by the service staff. This was foreseen in the study protocol and approved by the ethical board. Data from the questionnaire and the patient records were linked using a unique anonymous identification number assigned to each person included via an anonymised patient record file.

\section{Data and statistical analyses}

In the implementation study for which the data were collected, the primary goal was self-evaluation of the care provided by the different teams. Therefore, we did not calculate any power. All completed and anonymised questionnaires were returned to the investigator KL for analysis. The investigator KL cleaned the data file and checked for accuracy before we performed the data analyses for this study.

Bivariate cross-tabulations were calculated to study associations between the perceptions of the family carers about the care, support, information and aftercare they had received from professional carers on the one hand, and the sociodemographic characteristics of the person who was dying and the type of SPCS and duration of care on the other hand. Variables that were bivariately associated with a family carer's perceptions (analyses not shown in this paper) were included in a 
Table 1 Overview of participating bereaved family carers

\begin{tabular}{|c|c|c|c|c|c|}
\hline \multirow{2}{*}{\multicolumn{2}{|c|}{ Breakdown of included participants }} & \multicolumn{4}{|c|}{ Type of palliative care service used } \\
\hline & & \multirow{2}{*}{$\frac{\mathrm{PCU}}{\mathrm{n}(\%)}$} & \multirow{2}{*}{$\begin{array}{l}\text { PST } \\
\mathrm{n}(\%)\end{array}$} & \multirow{2}{*}{$\begin{array}{l}\mathrm{HCT} \\
\mathrm{n}(\%)\end{array}$} & \multirow{2}{*}{$\begin{array}{l}\text { Total } \\
\mathrm{n}(\%)\end{array}$} \\
\hline & & & & & \\
\hline \multicolumn{2}{|c|}{ Family carers receiving a questionnaire } & 1478 & 1352 & 195 & 3025 \\
\hline \multicolumn{2}{|l|}{ Responding } & $883(59.74)$ & $634(46.89)$ & $100(51.28)$ & $\begin{array}{l}1617 \\
(53.45)\end{array}$ \\
\hline \multicolumn{2}{|l|}{ Of whom primary family carer* } & 824 & 585 & 95 & 1504 \\
\hline \multirow[t]{4}{*}{ Measurement period } & November 2014 & 129 & 80 & 0 & 209 \\
\hline & May 2015 & 232 & 198 & 27 & 457 \\
\hline & November 2015 & 231 & 127 & 30 & 388 \\
\hline & May 2016 & 232 & 180 & 38 & 450 \\
\hline \multirow[t]{2}{*}{ Sex } & Male & $417(51.42)$ & $292(50.78)$ & $61(67.78)$ & $770(52.17)$ \\
\hline & Female & $394(48.58)$ & $283(49.22)$ & $29(32.22)$ & $706(47.83)$ \\
\hline \multirow[t]{4}{*}{ Age (years) } & $18-59$ & $94(11.62)$ & $45(8.01)$ & $13(14.44)$ & $152(10.40)$ \\
\hline & $60-74$ & $273(33.75)$ & $170(30.25)$ & $40(44.44)$ & $483(33.06)$ \\
\hline & $75-84$ & $273(33.75)$ & $187(33.27)$ & $27(30.00)$ & $487(33.33)$ \\
\hline & 85 or older & $169(20.89)$ & $160(28.47)$ & $10(11.11)$ & $339(23.20)$ \\
\hline \multirow[t]{5}{*}{ Relation of family carer to patient } & Partner & $348(42.39)$ & $257(44.70)$ & $70(74.47)$ & $675(45.30)$ \\
\hline & Son/daughter (in law) & $351(42.75)$ & $259(45.04)$ & $19(20.21)$ & $629(42.21)$ \\
\hline & Parent & $14(1.71)$ & $3(0.52)$ & 0 & $17(1.14)$ \\
\hline & Other family & $92(11.21)$ & $51(8.87)$ & $5(5.32)$ & $148(9.93)$ \\
\hline & No family & $16(1.95)$ & $5(0.87)$ & 0 & $21(1.41)$ \\
\hline \multirow[t]{2}{*}{ Cancer } & Yes & $619(88.30)$ & $239(50.00)$ & $59(85.51)$ & $917(73.48)$ \\
\hline & No & $82(11.70)$ & $239(50.00)$ & $10(14.49)$ & $331(26.52)$ \\
\hline \multirow[t]{3}{*}{ Length of service enrolment } & 3 days or less & $193(23.80)$ & $221(38.37)$ & $9(10.00)$ & $423(28.64)$ \\
\hline & 4 days -2 weeks & $336(41.43)$ & $176(30.56)$ & $14(15.56)$ & $526(35.61)$ \\
\hline & More than 2 weeks & $282(34.77)$ & $179(31.08)$ & $67(74.44)$ & $528(35.75)$ \\
\hline
\end{tabular}

${ }^{*}$ As indicated by the family carer completing the questionnaire.

HCT, home care team; PCU, palliative care unit; PST, palliative support team.

binary logistic regression model for each of the nine questionnaire items to verify these associations while controlling for all other related characteristics simultaneously. The level of statistical significance was set at $<0.05$. Statistical analyses were performed in IBM SPSS Statistics V.24.0.

\section{Ethics}

All participants who filled out a questionnaire gave their consent to the study. In the information letter they received, we explained the nature of the study, the data analysis, the anonymisation procedure, as well as the voluntary nature of their participation. Participants were explained they could stop filling out the questionnaire or withdraw from the study at any time.

All participants were assigned an anonymous number. During and after the data collection, anonymity was preserved; the completed questionnaires received by the researchers could never be linked to identifying information, since the palliative care services were responsible for distributing the questionnaires and keeping the personal information.

\section{RESULTS}

The response rate of the family carers contacted was $53.5 \%$. This resulted in a sample of 1504 respondents who had indicated they were the primary family carer. The sample characteristics are shown in table 1 . These demonstrate that people whose family carers were recruited through HCTs were more often men, younger than 85 years and enrolled during a longer period.

\section{Support provided to family carers by SPCS}

Of all respondents, $86.1 \%$ indicated having received the support required to provide care for someone close. About three-quarters of the family carers (77.7\%) affirmed that they were frequently asked by professional carers how they were feeling and $66.8 \%$ that they were asked more than once what caring for the person meant to them. Approximately three out of four respondents indicated having received the right amount of information about the patient's condition (75.3\%), the impending death (74.2\%) and the possible benefits and risks of treatment options $(75.5 \%)$. The perception of being provided with an insufficient amount of any of these types of information was 
Table 2 Multivariate analysis: characteristics associated with support by professional carer

\begin{tabular}{|c|c|c|c|c|}
\hline \multicolumn{2}{|c|}{ Patient and service characteristics } & \multicolumn{3}{|c|}{ OR $(95 \% \mathrm{Cl})$ for how professional carers supported family carers } \\
\hline & & & & Talk to them about \\
\hline & & & Ask how they are & what it means to \\
\hline & & Give all help/support & feeling & provide care \\
\hline & & they need & (often vs not & (often vs not more \\
\hline & & (yes vs no) & more than once) & than once) \\
\hline \multirow[t]{2}{*}{ Sex } & Male & $0.616(0.437$ to 0.868$)$ & & \\
\hline & Female & Ref & & \\
\hline \multirow[t]{5}{*}{ Relation to patient } & Partner & & Ref & \\
\hline & Son/daughter (in law) & & $0.812(0.592$ to 1.112$)$ & \\
\hline & Parent & & $1.128(0.239$ to 5.324$)$ & \\
\hline & Other family member & & $0.318(0.203$ to 0.498$)$ & \\
\hline & No family & & 0.637 (0.199 to 2.040$)$ & \\
\hline \multirow[t]{2}{*}{ Cancer } & Yes & 0.730 (0.497 to 1.072$)$ & 0.906 (0.641 to 1.281$)$ & 0.912 (0.671 to 1.239$)$ \\
\hline & No & Ref & Ref & Ref \\
\hline \multirow[t]{3}{*}{ Service type } & PCU & Ref & Ref & Ref \\
\hline & PST & $0.159(0.107$ to 0.238$)$ & $0.296(0.213$ to 0.411$)$ & $0.356(0.269$ to 0.471$)$ \\
\hline & $\mathrm{HCT}$ & $0.460(0.213$ to 0.993$)$ & $0.482(0.249$ to 0.932$)$ & 0.588 (0.337 to 1.024$)$ \\
\hline \multirow[t]{3}{*}{ Duration of enrolment } & $<4$ days & & Ref & Ref \\
\hline & 4 days -2 weeks & & $1.130(0.791$ to 1.613$)$ & $1.208(0.882$ to 1.654$)$ \\
\hline & $>2$ weeks & & 1.507 (1.047 to 2.169$)$ & 1.361 (0.991 to 1.868$)$ \\
\hline
\end{tabular}

The variable 'age' was excluded from the analyses shown, as no significant relationship was identified in the bivariate analyses between this variable and support provided by professional carers.

HCT, home care team; PCU, palliative care unit; PST, palliative support team.

about as common as receiving too much information. Of all family carers, $56.1 \%$ were notified of available bereavement support and 91.4\% felt supported by professional carers immediately after bereavement. For $39.4 \%$, a farewell or staff appraisal was held to look back to the care and treatment provided by the palliative care service.

\section{Factors associated with support for family carers}

Multivariable logistic regression analyses simultaneously controlling for the effects of all bivariately related characteristics (tables 2-4) indicated that sons or daughters (in law) were more likely to be adequately informed about the impending death than was the partner of the person who was dying $(\mathrm{OR}=1.362$, 95\% CI 1.006 to 1.842 ). Conversely, family carers of people aged 18-59 years were less likely to be informed on this matter compared with those of people of 85 years or older (OR $=0.595,95 \%$ CI 0.369 to 0.960$)$. The family carers of people who died under a PST were less likely than those who died in a PCU to receive the required amount of any type of information, support and aftercare (ORs varying from 0.109 to $0.710,95 \%$ CIs ranging from 0.062 to 0.908 ). Similarly, family carers of people who died under an HCT were less likely than those under a PCU to be asked how they were feeling $(\mathrm{OR}=0.482,95 \% \mathrm{CI} 0.249$ to 0.932$)$, receive the help and support required before $(\mathrm{OR}=0.460,95 \% \mathrm{CI} 0.213$ to 0.993$)$ and immediately after $(\mathrm{OR}=0.158,95 \% \mathrm{CI}$ 0.067 to 0.373 ) death, receive the right amount of information about the impending death $(\mathrm{OR}=0.416$, $95 \%$ CI 0.255 to 0.679 ) and to be informed about the options of aftercare $(\mathrm{OR}=0.573,95 \%$ CI 0.340 to 0.966). In contrast, a farewell or staff appraisal after death to evaluate the care provided was more likely in an HCT than in a PCU $(\mathrm{OR}=1.814,95 \%$ CI 1.065 to 3.090). Table 5 describes the differences between the three types of SPCSs in more detail.

\section{DISCUSSION}

Main findings

This study demonstrates that about $86 \%$ of all family carers of people who used a specialised palliative home or hospital care service felt supported by professional carers prior to the death. Approximately three out of four respondents indicated having received the right amount of information about the condition of the person who was dying, the pros and cons of treatment and the imminence of the death. Even though about 9 out of 10 family carers also felt supported immediately after death, almost half of them indicated not having received any information about the possibilities of aftercare. Family carers were more likely to receive support and care when the person who was dying was supported in a hospital's PCU than by a palliative HCT or a mobile PST in the hospital.

\section{Meaning of the findings and implications for policy, practice and research}

In general, family carers appear to receive a relatively high degree of support at the end of the life of the 
Table 3 Multivariate analysis: characteristics associated with information provision by professional carers

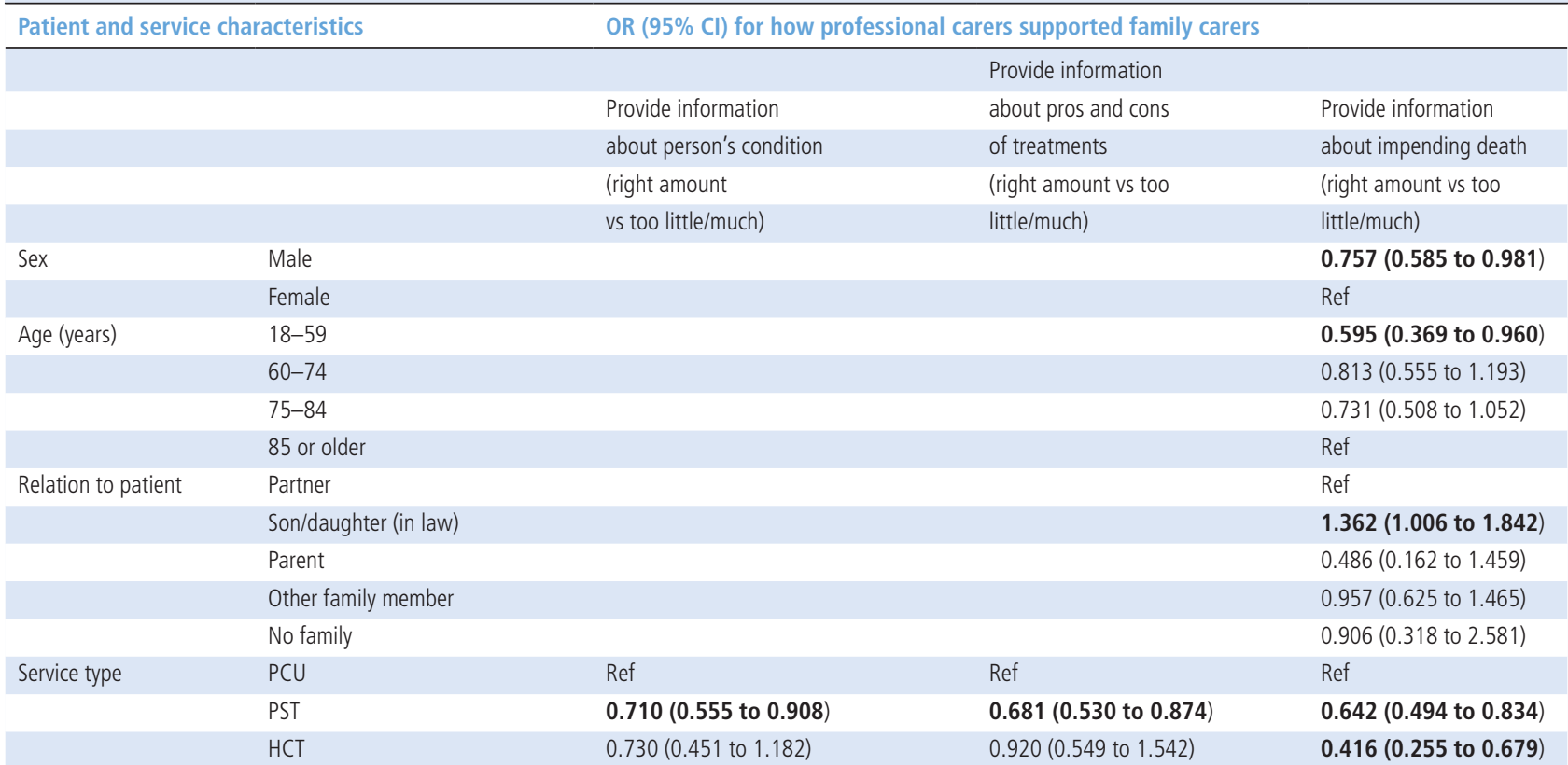

The variables 'cancer' and 'duration of enrolment' were excluded, as no significant relationships were identified in the bivariate analyses between these variables and information provided by professional carers.

HCT, home care team; PCU, palliative care unit; PST, palliative support team.

person for whom they are caring. Nonetheless, approximately one in every seven does not feel sufficiently supported and about a quarter indicated they had not received sufficient information. Given that palliative care should always be aimed at both the person who is dying and those close to them, ${ }^{17}$ we believe that there is still room for improvement across all types of SPCSs. Hudson $e t a l^{30}$ have formulated principles and guidelines for multidisciplinary healthcare professionals who regularly provide palliative care on how family carers should be supported during and after the illness and death of a relative. Clear communication with family carers about the severity of the illness, raising awareness that death is near and evaluating the family's preparedness for death are postulated as fundamental palliative care practices. Therefore, we advise that all SPCSs incorporate these principles in their procedures and implement them as quality indicators to evaluate and follow-up on the support provided to family carers. Additionally, as many people do not access SPCSs, future research could also compare our findings with family carers' perception of support from non-specialised services.

Researchers have also recommended that during the period before and after death, family carers should be informed about the availability of bereavement

Table 4 Multivariate analysis: characteristics associated with aftercare provision by professional carers

\begin{tabular}{|c|c|c|c|c|}
\hline \multicolumn{2}{|c|}{ Patient and service characteristics } & \multicolumn{3}{|c|}{ OR $(95 \% \mathrm{CI})$ for how professional carers supported family carers } \\
\hline & & Family carer feels & & Farewell or staff appraisal \\
\hline & & supported immediately & Possibilities of aftercare & Interview looking back on \\
\hline & & after death & pointed out after death & care and treatment provided \\
\hline & & (yes vs no) & (yes vs no) & (yes vs no) \\
\hline \multirow[t]{2}{*}{ Sex } & Male & $0.522(0.334$ to 0.816$)$ & & \\
\hline & Female & Ref & & \\
\hline \multirow[t]{2}{*}{ Cancer } & Yes & $0.872(0.544$ to 1.398$)$ & 1.160 (0.869 to 1.548$)$ & $0.856(0.627$ to 1.169$)$ \\
\hline & No & Ref & Ref & Ref \\
\hline \multirow[t]{3}{*}{ Service type } & PCU & Ref & Ref & Ref \\
\hline & PST & $0.109(0.062$ to 0.193$)$ & $0.448(0.344$ to 0.584$)$ & $0.423(0.318$ to 0.563$)$ \\
\hline & HCT & $0.158(0.067$ to 0.373$)$ & $0.573(0.340$ to 0.966$)$ & 1.814 (1.065 to 3.090$)$ \\
\hline \multirow[t]{3}{*}{ Duration of enrolment } & $<4$ days & & & Ref \\
\hline & 4 days -2 weeks & & & 1.331 (0.975 to 1.817$)$ \\
\hline & $>2$ weeks & & & $1.166(0.850$ to 1.600$)$ \\
\hline
\end{tabular}

The variables 'age' and 'relation to patient' were excluded, as no significant relationships were identified in the bivariate analyses between these variables and professional aftercare. HCT, home care team; PCU, palliative care unit; PST, palliative support team. 
Table 5 Types of support for family carers from each type of palliative care service

\begin{tabular}{|c|c|c|c|c|c|c|}
\hline & & Total & PCU & PST & $\mathrm{HCT}$ & \\
\hline & & $\mathrm{n}(\%)$ & n $(\%)$ & $\mathrm{n}(\%)$ & $\mathrm{n}(\%)$ & $\mathrm{P}^{*}$ \\
\hline Gave all help and support needed for FC & Yes & $1272(86.1)$ & 767 (93.9) & $421(74.3)$ & $84(89.4)$ & $<0.001$ \\
\hline & No & $206(13.9)$ & $50(6.1)$ & $146(25.7)$ & $10(10.6)$ & \\
\hline Asked how FC was feeling & Yes, more than once & $1154(77.7)$ & $699(85.7)$ & $378(65.9)$ & $77(81.1)$ & $<0.001$ \\
\hline & No or only once & $331(22.3)$ & $117(14.3)$ & $196(34.1)$ & $18(18.9)$ & \\
\hline Talked about what it meant for FC to & Yes, more than once & $971(66.8)$ & $603(75.5)$ & $303(53.8)$ & $65(70.7)$ & $<0.001$ \\
\hline & No or only once & $483(33.2)$ & $196(24.5)$ & $260(46.2)$ & $27(29.3)$ & \\
\hline Information about condition & Right amount & $1121(75.3)$ & $641(78.2)$ & $412(71.8)$ & $68(72.3)$ & $=0.019$ \\
\hline & Less or more than necessary & $367(24.7)$ & $179(21.8)$ & $162(28.2)$ & $26(27.7)$ & \\
\hline Information about pros and cons of & Right amount & $1083(75.5)$ & $616(78.4)$ & $397(71.1)$ & $70(76.9)$ & $=0.010$ \\
\hline & Less or more than necessary & $352(24.5)$ & $170(21.6)$ & $161(28.9)$ & $21(23.1)$ & \\
\hline Information about impending death & Right amount & $1057(74.2)$ & $618(78.5)$ & $391(70.8)$ & $48(56.5)$ & $<0.001$ \\
\hline & Less or more than necessary & $367(25.8)$ & $169(21.5)$ & $161(29.2)$ & $37(43.5)$ & \\
\hline FC felt supported immediately after & Yes & $1273(91.4)$ & 779 (97.4) & $422(82.6)$ & $72(87.8)$ & $<0.001$ \\
\hline & No & $120(8.6)$ & $21(2.6)$ & $89(17.4)$ & $10(12.2)$ & \\
\hline Possibilities of aftercare pointed out & Yes & $806(56.1)$ & $521(65.4)$ & $235(42.3)$ & $50(58.1)$ & $<0.001$ \\
\hline & No & $632(43.9)$ & $276(34.6)$ & $320(57.7)$ & $36(41.9)$ & \\
\hline Farewell or staff appraisal looking back & Yes & $563(39.4)$ & $362(46.2)$ & $147(26.4)$ & $54(60.0)$ & $<0.001$ \\
\hline & No & $866(60.6)$ & $421(53.8)$ & 409 (73.6) & $36(40.0)$ & \\
\hline
\end{tabular}

${ }^{*} \chi^{2}$ analyses for differences across the three types of services for the responses given to each question.

FC, family carer;HCT, home care team; PCU, palliative care unit; PST, palliative support team.

support initiatives ${ }^{30-32}$ as they could benefit from knowing what support services exist and who they can turn to if they want to talk or share experiences or have practical issues or suffer from prolonged grief. Nevertheless, our study shows that almost half of all family carers do not receive information about their options for aftercare. These results may be explained by a lack of formal guidelines on bereavement support, which are not available in two out of three European SPCSs. ${ }^{24}$ In Belgian legislation, providing or helping to find aftercare is also, at the moment, not considered a clear core task of these services ${ }^{33-36}$ and therefore is not linked to funding, which might account for the lack of bereavement support offered. However, during the process of developing quality indicators, palliative care experts across different countries have confirmed aftercare to be a vital aspect of high-quality palliative care $^{2837}$ and, therefore, SPCSs can at least be expected to provide some guidance for bereaved family carers. Palliative care services may efficiently address the lack of information on aftercare by developing and spreading brochures aimed at bereaved family caregivers. For more extensive bereavement support, changes in palliative care legislation and in the mission statement and funding of SPCSs are necessary.

Another noticeable finding is that family carers receive more adequate information and feel better supported, both before and after the death, when death takes place in a PCU. This is in line with the outcomes from an Australian study demonstrating that family carers were most satisfied with the support they received in an inpatient palliative care setting. ${ }^{38}$ The differences identified in our study between palliative care settings suggest that the care provided in PCUs could serve as an example for the support provided to family carers. PCUs may not directly act as a benchmark for the other services, however, as different types of SPCSs address distinct needs. The main purpose of HCTs and PSTs is to provide regular professional carers with advice and support on providing palliative care for people who are confronted with serious illness, although in practice these types of services also provide more direct care themselves. In contrast, it is typical for a PCU that in-house expertise in palliative care is readily available around the clock, ${ }^{39}$ with the interdisciplinary staff being exclusively composed of skilled palliative care professionals whose main role is to provide terminal care directly to the dying person and those close to them. Further research is required to assess how HCTs and PSTs can improve the support provided to family carers.

Lastly, our findings suggest that palliative care services tend to communicate bad news more to 
younger relatives, as well as with children of the person who is dying. Some healthcare providers may believe that older adults are less capable of processing negative messages and therefore turn to the children of the dying person. In palliative care, systematic discrimination against people because of their age, that is, ageism, ${ }^{40}$ has been observed in patient care and communication. A recent study conducted in Sweden by Lindskog et al, ${ }^{41}$ for example, demonstrates that both the dying person and their family members were less likely to be informed about the imminence of death when the former was old. Further research is required to corroborate our finding that ageism in communication is related to the age of the dying person's relatives. If this finding is confirmed, then palliative care services should be mindful of ageism in their organisation and make sure that clinicians get accustomed to breaking bad news to all involved family carers. Currently, research about the efficacy of possible interventions to counter ageism in healthcare is scarce, so future research could study the attitudes of palliative care providers towards older family members as well and explore what other interventions may be effective in tackling ageism in healthcare.

\section{Strengths and weaknesses}

The large sample of bereaved family carers and the relatively high response rate were major strengths of this survey study. By collecting data through both palliative home care services and hospital-based palliative care services, this study was able to measure diverse experiences with specialised palliative care in Flanders. In addition, our questionnaire gauged the support that family carers had received both before and after the death. This study also has some limitations. First, the questionnaire does not allow us to identify the specific professional carer within the service who provided family carers with support. Second, it was not assessed how often family carers had contact with professional care providers, although in our analyses, we did control for the length of enrolment. Third, as the survey exclusively focused on the perspectives of family carers, professional carers' experiences were not examined, though this could have provided additional insights into how these compare with family perceptions of the support provided. Fourth, our sample may not be representative of SPCSs in Flanders, as selection of services was based on participation in the quality indicators project. ${ }^{25}{ }^{26}$ Having a large sample of 34 services mitigates this limitation. However, while the number of participating HCTs is proportionate in our sample, due to practical difficulties and time management issues within these teams, participants who had received care from HCTs are somewhat under-represented in our sample. Finally, our study does not include a comparison between people who had access to SPCSs and those who had received non-specialised palliative care.

\section{CONCLUSION}

Family carers of people supported by palliative care services seem to have a positive evaluation of the assistance they receive at the end of life and during bereavement. However, this evaluation was substantially more positive when care was received in a PCU where palliative care professionals are available 24 hours a day. The support for family carers in this setting could become a benchmark for other palliative care services, although policy reforms may be needed to attain this level of care in different settings.

Acknowledgements The authors would like to thank all participating palliative care services and Jane Ruthven for her language editing. This work has been previously presented at the 10th World Research Congress of the EAPC in Bern (Switzerland, May 2018) and at the international 'Public Health Research in Palliative Care: Shifting the Paradigm' seminar in Brussels (Belgium, October 2018).

Contributors $\mathrm{KL}, \mathrm{LVdB}, \mathrm{LD}$ and JC contributed to the study concept, study design and data collection. MV, ADV and KL contributed to the statistical analysis. MV drafted the manuscript with input from all authors. The final manuscript was read and approved by all authors.

Funding This study is supported by a grant from the Flemish government agency for Innovation by Science and Technology (agentschap voor Innovatie door Wetenschap en Technologie, SBO IWT nr. 140009).

Competing interests None declared.

Patient consent for publication Not required.

Ethics approval The study protocol, detailing procedures on measurement and data collection, was approved by the University Ethical Review Board and by the local ethical board of every hospital participating in the measurement.

Provenance and peer review Not commissioned; externally peer reviewed.

Data sharing statement Data are available upon reasonable request.

\section{REFERENCES}

1 Emanuel EJ, Fairclough DL, Slutsman J, et al. Assistance from family members, friends, paid care givers, and volunteers in the care of terminally ill patients. N Engl J Med 1999;341:956-63.

2 National Alliance for Caregiving, AARP Public Policy Institute. Caregiving in the U.S. 2015. Available: https://www.aarp.org/ content/dam/aarp/ppi/2015/caregiving-in-the-united-states2015-report-revised.pdf. [Accessed January 29, 2019.].

3 Wolff JL, Dy SM, Frick KD, et al. End-of-life care: findings from a national survey of informal caregivers. Arch Intern Med 2007;167:40-6.

4 Henriksson A, Carlander I, Årestedt K. Feelings of rewards among family caregivers during ongoing palliative care. Pall Supp Care 2015;13:1509-17.

5 Harding R, Epiphaniou E, Hamilton D, et al. What are the perceived needs and challenges of informal caregivers in home cancer palliative care? qualitative data to construct a feasible psycho-educational intervention. Support Care Cancer 2012;20:1975-82.

6 Stajduhar KI, Funk L, Toye C, et al. Part 1: home-based family caregiving at the end of life: a comprehensive review 
of published quantitative research (1998-2008). Palliat Med 2010;24:573-93.

7 Dionne-Odom JN, Azuero A, Lyons KD, et al. Benefits of early versus delayed palliative care to informal family caregivers of patients with advanced cancer: outcomes from the enable III randomized controlled trial. JCO 2015;33:1446-52.

8 Northouse LL, Katapodi MC, Song L, et al. Interventions with family caregivers of cancer patients: meta-analysis of randomized trials. CA Cancer J Clin 2010;60:317-39.

9 Payne S, Hudson P, Grande G, et al. White paper on improving support for family carers in palliative care: Part 2. Eur J Palliat Care 2010;17:286-90.

10 Connolly J, Milligan SD. Knowledge and skills needed by informal carers to look after terminally ill patients at home. End of Life Journal 2014;4:1-14.

11 Henriksson A, Årestedt K. Exploring factors and caregiver outcomes associated with feelings of preparedness for caregiving in family caregivers in palliative care: a correlational, cross-sectional study. Palliat Med 2013;27:639-46.

12 Hudson P, Thomas T, Quinn K, et al. Teaching family carers about home-based palliative care: final results from a group education program. Journal of Pain and Symptom Management 2009;38:299-308.

13 Kim Y, Carver CS, Spiegel D, et al. Role of family caregivers' self-perceived preparedness for the death of the cancer patient in long-term adjustment to bereavement. Psycho-Oncology 2017;26:484-92.

14 National Institute for Clinical Excellence. Improving supportive and palliative care for adults with cancer: the manual, 2004. Available: https://www.nice.org.uk/guidance/ $\operatorname{csg} 4 /$ resources/improving-supportive-and-palliative-care-foradults-with-cancer-pdf-773375005 [Accessed 29 Jan 2019].

15 Federale Evaluatiecel Palliatieve Zorg. Evaluatierapport palliatieve zorg [Evaluation Report on Palliative Care of the Federal Evaluation Cell on Palliative Care], 2014. Available: https://overlegorganen.gezondheid.belgie.be/sites/default/files/ documents/pz_rapport_2017_.docx_.pdf [Accessed 29 Jan 2019].

16 World Health Organization. Planning and implementing palliative care services: a guide for programme managers, 2016. Available: http://www.who.int/iris/handle/10665/250584 [Accessed 29 Jan 2019].

17 Sepúlveda C, Marlin A, Yoshida T, et al. Palliative care: the World Health Organization's global perspective. J Pain Symptom Manage 2002;24:91-6.

18 Andershed B. Relatives in end-of-life care - Part 1: a systematic review of the literature the five last years, January 1999February 2004. J Clin Nurs 2006;15:1158-69.

19 Aoun SM, Deas K, Howting D, et al. Exploring the support needs of family caregivers of patients with brain cancer using the CSNAT: a comparative study with other cancer groups. Plos One 2015;10:e145106.

20 Wilkes L, White K, O'Riordan L. Empowerment through information: supporting rural families of oncology patients in palliative care. Aust J Rural Health 2000;8:41-6.

21 Shield RR, Wetle T, Teno J, et al. Physicians "missing in action": family perspectives on physician and staffing problems in end-of-life care in the nursing home. J Am Geriatr Soc 2005;53:1651-7.

22 Bee PE, Barnes P, Luker KA. A systematic review of informal caregivers' needs in providing home-based end-of-life care to people with cancer. J Clin Nurs 2009;18:1379-93.

23 Proot IM, Abu-Saad HH, Crebolder HFJM, et al. Vulnerability of family caregivers in terminal palliative care at home; balancing between burden and capacity. Scand J Caring Sci 2003;17:113-21.
24 Guldin M-B, Murphy I, Keegan O, et al. Bereavement care provision in Europe: a survey by the EAPC bereavement care Taskforce. Eur J Palliat Care 2015;22:185-9.

25 Leemans K, Deliens L, Francke AL, et al. Quality indicators for palliative care services: Mixed-method study testing for face validity, feasibility, discriminative power and usefulness. Palliat Med 2015;29:71-82.

26 Leemans K, Cohen J, Francke AL, et al. Towards a standardized method of developing quality indicators for palliative care: protocol of the quality indicators for palliative care (Q-PAC) study. BMC Palliative Care 2013;12.

27 Claessen SJJ, Francke AL, Sixma H, et al. Op weg naar een CQ-index Palliatieve Zorg: meetinstrumentontwikkeling [Towards a CQ-index Palliative Care: instrument development], 2009. Available: https://nvl004.nivel.nl/ nivel-2015/sites/default/files/bestanden/Rapport-CQ-indexPalliatieve-Zorg.pdf [Accessed 29 Jan 2019].

28 Claessen SJJ, Francke AL, Belarbi HE, et al. A new set of quality indicators for palliative care: process and results of the development trajectory. Journal of Pain and Symptom Management 2011;42:169-82.

29 Addington-Hall J, Walker L, Jones C, et al. A randomised controlled trial of postal versus interviewer administration of a questionnaire measuring satisfaction with, and use of, services received in the year before death. Journal of Epidemiology \& Community Health 1998;52:802-7.

30 Hudson P, Remedios C, Zordan R, et al. Guidelines for the psychosocial and bereavement support of family caregivers of palliative care patients. Journal of Palliative Medicine 2012;15:696-702.

31 Aoun SM, Breen LJ, O'Connor M, et al. A public health approach to bereavement support services in palliative care. Aust N Z J Public Health 2012;36:14-16.

32 Hudson P, Hall C, Boughey A, et al. Bereavement support standards and bereavement care pathway for quality palliative care. Palliat Support Care 2017:1-13.

33 Belgian Ministry of Social Affairs, Public Health and Environment. Koninklijk besluit van 15 juli 1997 tot wijziging van het koninklijk besluit van 23 oktober 1964 tot bepaling van de normen die door de ziekenhuizen en hun diensten moeten worden nageleefd [Royal Decree of July 15, 1997 for the modification of the Royal Decree of October 23, 1964 for the stipulation of the norms that should be met by hospitals and their services], publication number 1997071534. Belgian Official Gazette, 1997.

34 Belgian Ministry of Social Affairs, Public Health and Environment. Koninklijk besluit van 15 juli 1997 waarbij sommige bepalingen van de wet op de ziekenhuizen, gecoördineerd op 7 augustus 1987, toepasselijk worden verklaard op de functie van palliatieve zorg [Royal Decree of July 15, 1997 trough which some regulations of the law for hospitals, coordinated on August 7, 1987, are declared applicable for the function of palliative care], publication number 1997071536. Belgian Official Gazette, 1997.

35 Belgian Ministry of Social Affairs, Public Health and Environment. Koninklijk besluit van 13 oktober 1998 tot bepaling van de minimale criteria waaraan de overeenkomsten tussen de multidisciplinaire begeleidingsequipes voor palliatieve verzorging en het Verzekeringscomité ingesteld bij de Dienst voor geneeskundige verzorging van het Rijksinstituut voor ziekte- en invaliditeitsverzekering moeten voldoen [Royal Decree of October 13, 1998 determining the minimum criteria that should be met by agreements between multidisciplinary home care teams for palliative care and the Insurance Committee established in the Service for medical care of the National institute for sickness benefits or invalidity allowance], publication number 1998101336. Belgian Official Gazette, 1998. 
36 Belgian Ministry of Social Affairs, Public Health and Environment. Koninklijk besluit van 19 februari 2002 tot wijziging van het koninklijk besluit van 15 juli 1997 waarbij sommige bepalingen van de wet op de ziekenhuizen, gecoördineerd op 7 augustus 1987, toepasselijk worden verklaard op de functie van palliatieve zorg [Royal Decree of February 19, 2002 that changes the Royal Decree of July 15, 1997, trough which some regulations of the law for hospitals, coordinated on August 7, 1987 are declared applicable for the function of palliative care], publication number 2002021934. Belgian Official Gazette, 2002.

37 Leemans K, Deliens L, Van den Block L, et al. Systematic quality monitoring for specialized palliative care services: development of a minimal set of quality indicators for palliative care study (QPAC). Am J Hosp Palliat Care 2017;34:532-46.

38 Pidgeon TM, Johnson CE, Lester L, et al. Perceptions of the care received from Australian palliative care services: a caregiver perspective. Pall Supp Care 2018;16:198-208.

39 Roza KA, Lee EJ, Meier DE, et al. A survey of bereaved family members to assess quality of care on a palliative care unit. $J$ Palliat Med 2015;18:358-65.

40 Robert NB. Why survive? Being old in America. Oxford, England: Harper \& Row, 1975.

41 Lindskog M, Tavelin B, Lundström S. Old age as risk indicator for poor end-of-life care quality - a population-based study of cancer deaths from the Swedish register of palliative care. Eur J Cancer 2015;51:1331-9. 